\title{
Periodontal disease and its impact in Latin America
}

\section{Giuseppe Alexandre Romito}

LAOHA President

Declaration of Interests: The authors certify that they have no commercial or associative interest that represents a conflict of interest in connection with the manuscript.

Submitted: January 28, 2020

Accepted for publication: January 31, 2020

Last revision: March 2, 2020
Following the example of work done by some dental associations around the world, in which meetings of opinion leaders in the field are promoted to discuss and establish parameters related to some condition or treatment in the area of dentistry, ${ }^{1}$ the Latin American Oral Health Association (LAOHA), which is supported by Colgate-Palmolive, promoted the first Workshop on Periodontal Conditions in the Latin-American and Caribbean Region, in 2019.

This initiative assembled professionals and opinion leaders of the academic area, class and specialty associations and government agencies. The discussion involved topics such as Prevention, Diagnosis, Treatment Plans and Epidemiological data of Latin America. Resulting from this debate, a Consensus was structured, which we have the privilege of publishing as a special supplement in Brazilian Oral Research.

The importance of this type of initiative is to bring to light scientific data and guidance with respect to a certain geographical area, because although we live in a globalized world, as far as conditions of health are concerned, regional particularities related to socio-cultural conditions are important, as they enable patients to be envisioned within their social context, which may have a direct impact on their condition of health and disease.

Disclosure of this Consensus throughout the Latin American and Caribbean region is fundamental to enable the professionals who work at whatever level, ranging from the private clinic through to government agencies, to understand the reality of periodontal conditions. As a result, they will be able to promote changes in public health, by basing their decision making on the most up-to-date data of existent scientific evidence.

\section{References}

\footnotetext{
1. Chapple ILC, Mealey BL, Van Dyje TE, Bartold PM, Dommisch H, Eickholz P, et al. Periodontal health and gingival diseases and conditions on an intact and a reduced periodontium: Consensus report of workgroup 1 of the 2017 World Workshop on the Classification of Periodontal and Peri-Implant Diseases and Conditions. J Clin Periodontol. 2018;89(Suppl 1):S74-84. https://doi.org/10.1002/JPER.17-0719
} 